\title{
Die Regieanzgaben Der
}

Bayerijđ̆en Geridhte, Bezirfsämter und $\Re e n t a ̈ \mathfrak{m} t \mathfrak{e r}$

\author{
Bon \\ $\mathcal{O B c a r}$ Gendtner \\ R. Oberregierungsirat am Oberften Rednungşgofe \\ in Münden
}

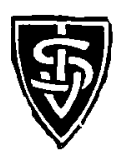

1914

Mänđhen, Berlin und Leipzitg

I. Gaweizer $\mathfrak{B} e r l a g ~(\mathfrak{A t h u r}$ Gellier). 


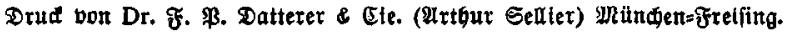

